\title{
Utilization of Fine Water Sprays in Explosion Mitigation: Cold Trial
}

S.A. Johnston ${ }^{1}$, G.G. Nasr ${ }^{2}$, and A. Nourian ${ }^{2 *}$

1. Department of Gas Engineering, Specialist Gas Assessment Services (SGAS), Blackpool, UK

2. Spray Research Group (SRG), School of Science, Engineering and Environment (SEE), University of Salford, Manchester, UK

\section{Abstract}

For the past fifty years, there has been a great deal of interest using water-based explosion suppression systems in mitigating the impact of thermal explosions and their consequential overpressures. Previous researches focused on the suppression and mitigation with sprays containing droplets $200 \mu \mathrm{m} \leq \mathrm{D} 32 \leq 1000 \mu \mathrm{m}$. The present study is focused on the mitigation of slow-moving deflagrations with speeds of less than or equal to $30 \mathrm{~m} / \mathrm{s}$. Consequently, the droplets within the spray must be small enough to extract heat in the short finite moments that the flame and droplets interact at about $0.03 \mathrm{~ms}$ for a $1 \mathrm{~mm}$ thick flame front. Thus far, previous theoretical studies have suggested that droplets in the order of 10 to $20 \mu \mathrm{m}$ will be small enough to mitigate combustion without relying on further droplet break up, although experimental trials were not performed to validate these data. This investigation, however, is presenting the full details of qualitative and quantitative analysis of using Spill Return Atomizer (SRA) to provide fine water spray ranging from $17 \mu \mathrm{m} \leq \mathrm{D} 32 \leq 29 \mu \mathrm{m}$ without relying on further breakup. The spray cone angle was increased from 34.7 to 49.2 degree and the exit orifice flow rate was raised from 0.295 to $1.36 \mathrm{l} / \mathrm{min}$. Increasing the flow rate provided the required range of droplets

\footnotetext{
* Corresponding author: Dr Amir Nourian (a.nourian@salford.ac.uk)
}

ORCID: https://orcid.org/0000-0001-8998-2300 
with liquid volume flux of 0.011 to $0.047 \mathrm{~cm}^{3} / \mathrm{s} / \mathrm{cm}^{2}$ and mean droplet velocity of 0 to 21.4 $\mathrm{m} / \mathrm{s}$. Hence the resulting characteristics required to mitigate a propagating combustion wave.

\section{Key Words}

Explosion mitigation, fire suppression, combustion, fine water spray, water mist, spill return atomizer (SRA), methane-air mixture, premixed flames, 


\section{Introduction}

Regrettably, gas and vapor cloud explosions will always occur. This is partly due to the reactivity and flammability of the species and the increased risk of likelihood caused by contributing several factors, including engineering and human failures. Many national and international studies have been carried out over time to attempt to explain the mechanisms leading up to such proceedings and to categorize these events. Explosions are driven by the rate of expansion from reactant to product. This thermal expansion, which may normally be in the order of 1:8, can also produce expansions of 1:40 and may produce near and far field overpressures of up to 50 atmospheres (Nasr and Connor, 2014). For many new sites, including processing plants, refineries, oil, and gas platforms etc., a high percentage of the risk regarding events leading up to an explosion can be reduced, simply by following appropriate design criteria.

This is reinforced by providing an on-going safety risk management process and procedure, such as Control of Major Accident Hazards Regulations (COMAH) (Health and Safety Executive (HSE), 2015), which are statutory and enforceable in the UK. In most instances there will be an opportunity to improve existing sites by altering site layout and design, or by installing third party mitigation processes, such as water deluge and explosion venting measures. The overall assessment process in determining the suitability of a mitigation system must ensure that the conditions that favour the occurrence of such explosive events are reduced to acceptable levels. Financial budgets must be set to allow for appropriate initial design measures or alterations to existing sites, with an on-going commitment to risk management and a continuous review process.

The use of water sprays in explosion suppression and mitigation research has been previously carried out by many authors including, the American Bureaux of Mines, British Gas, GexCon and the University of Aberystwyth. Table 1 shows the focus of the previous work on the 
employment of atomizers and sprays and their suitability in producing appropriate spray characteristics, with mean droplet sizes (D32 $\geq 100 \mu \mathrm{m})$ and sufficient liquid volume flux to mitigate or suppress high speed explosions with propagating flame speeds ranging from 100 to $2000 \mathrm{~m} / \mathrm{s}$

Table 1: Typical representation of droplet densities reported in previous studies

\begin{tabular}{|l|c|c|}
\hline \multicolumn{1}{|c|}{ Author(s) } & $\begin{array}{c}\text { Droplet size, D32 } \\
(\boldsymbol{\mu m})\end{array}$ & Droplet density, $\boldsymbol{\rho d}$ \\
\hline Sapko et al. (1977) & 56,70 and 106 & $34.6,43.3$ and $68.8 \mathrm{~kg} / \mathrm{m}^{3}$ \\
\hline $\begin{array}{l}\text { Van Wingerden and Wilkins (1995) } \\
\text { and Van Wingerden et al. (1995) }\end{array}$ & 10 & $234 \mathrm{~g} / \mathrm{m}^{3}$ or $31.5 \% \mathrm{vol} / \mathrm{vol}$ \\
\hline $\begin{array}{l}\text { Corning and Wickens (1986) and } \\
\text { Johnson et al. (1991) }\end{array}$ & $600-800$ & Fw 0.02 and $0.005 \%$ \\
\hline Fleming and Sheinson (2007) & 27 and 116 & 36 and $70 \mathrm{~g} / \mathrm{m}^{3}$ \\
\hline Catlin (1991) & $600-800$ & Fw 0.02 and $0.005 \%$ \\
\hline Zalosh and Baipai (1982) & $20-100$ & $0.1-10 \mathrm{~kg} / \mathrm{m}^{3}$ \\
\hline
\end{tabular}

The flame speeds used in the previous research were generally representative of those associated with high loss incidents caused by flame acceleration and consequential high overpressures. With accelerated flame speeds the blast wave ahead of the combustion wave can provide the dynamic forces required to break up the water droplets into much smaller diameters. Mitigation of the flame or suppression of combustion activity only occurred in previous work when the dynamic forces created by the blast wave were great enough to overcome the surface tension forces in the water droplets. Fine mists formed by the hydrodynamic breakup of the larger droplets could then progress through the flame.

Providing that there was an adequate liquid volume flux $\left(\mathrm{Q}_{\mathrm{f}}\right)$ and sufficient 'residence time' $(\mathrm{t})$ for droplets in reaction zone of the flame to facilitate suppression or global mitigation of combustion, a high degree of success was reported. The previous studies exclusively concluded that water was found to be very effective in the suppression or mitigation of gas and vapor 
cloud explosions, even at supersonic flame speeds (or detonations) typically between 1500 to $2000 \mathrm{~m} / \mathrm{s}$.

In summarizing some of the previous studies, Harris and Wickens (1989) additionally highlighted significant areas of concern regarding water-based mitigation systems:

- The turbulence caused by water spray momentum may be transferred into the unburned mixture, or the flame front, thus causing turbulence and an overall increase in local or global flame speeds.

- Accidental water ingress into electrical apparatus and switch gear may lead to an electrical spark, which may cause re-ignition of a flammable mixture, or even cause secondary fires.

- Water storage volumes need to be large enough to provide uninterrupted sprays for very long periods.

It has become evident that previous water spray mitigation research exclusively relied on the subsequent break up of water droplets into fine mist. To achieve this, break up, the forces contained in the blast wave must be greater than the forces holding the droplets together in the first instance. In many instances, particularly when an explosion occurs in an unconfined area, overpressures may be as little as a few hundred Pascals (Pa), whereby water droplets would not initiate further break up, thus retaining their original geometry. Lane (1951) presented the following relationship between droplet diameter and the critical velocity needed to overcome the intrinsic forces i.e. surface tension, which hold droplets together.

$$
\left(V_{C}\right)^{2} d=0.612 \times 10^{6} \frac{\mathrm{m}^{3}}{\mathrm{~s}^{2}}
$$


Where, $V_{C}$ is the critical relative gas stream velocity for droplet break up $(\mathrm{m} / \mathrm{s})$ and $\mathrm{d}$ is the droplet diameter $(\mu \mathrm{m})$. Whereby, the surface tension of water is taken to be $73.10 \mathrm{mN} / \mathrm{m}$ and the gas mixture density is assumed to be $1.2 \mathrm{~kg} / \mathrm{m}^{3}$. Lane's formula is consistent with a critical Weber number stated by many authors of (Harris and Wickens, 1989, Lane, 1951, Zalosh and Bajpai, 1982) required for droplet break up.

Previous water spray studies have all concentrated on the conditions required to mitigate high speed explosions, in which the flow field is capable of shattering large water droplets into fine mist. Unconfined explosions where little or no obstructions are present are of particular interest to this current work, as the relatively slow associated flame speeds $(\leq 30 \mathrm{~m} / \mathrm{s})$ are incapable of breaking up water droplets any further. To supress or mitigate a slow-moving flame front, water droplets must initially be small enough $(\leq 30 \mu \mathrm{m})$ to directly absorb heat from the flame.

Due to the significant wealth of experimental research carried out in this study, the trials were subdivided into two distinct groups as 'cold-trials' and 'hot-trials'. The present investigation describes the 'cold-trials' which includes a series of dynamic non-intrusive laser measurements using Phase Doppler Anemometry (PDA) to study the spray behaviour under ambient conditions in the absence of a fuel-air mixture or propagating flame.

\section{Experimental Setup}

Within this investigation, there were several experimental challenges and achievements, including the design and fabrication of new apparatus and rigs, qualitative and quantitative collection procedures and methods of data and imagery processing. It is worth noting that due to the specific intentions and requirements of this study, rig designs used in other investigations (Catlin, 1991, Cornin and Wickens, 1986, Fleming and Sheinson, 2007, Johnson et al., 1991, $\underline{\text { Sapko et al., 1977, Van Wingerden and Wilkins, 1995, Van Wingerden et al., 1995, Zalosh and }}$ Bajpai, 1982) would be ineffective if emulated in this present research. 
As discussed previously, the aim and objectives of this research are quite different to previous studies, with the emphasis being to mitigate relatively slow-moving propagating flames with velocity below $30 \mathrm{~m} / \mathrm{s}$. The "cold trials" were designed to explore and develop an existing Spill Return Atomizer (SRA) which was previously designed by Nasr et al. (2011) and to provide a selection of suitable configurations that would be assessed in presence of flame, called "hot trials", within the purpose built 'Flame Propagation and Mitigation Rig (FPMR)'. Also, as previously discussed, earlier studies (Catlin, 1991, Cornin and Wickens, 1986, Fleming and

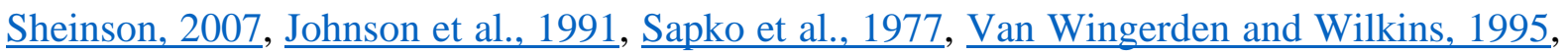
Van Wingerden et al., 1995, Zalosh and Bajpai, 1982) concentrated on the effects of the hydrodynamic breakup of large water droplets greater than $100 \mu \mathrm{m}$, with respect to explosion mitigation by water sprays. Whereas this present research is focused on the development of a fine spray system, consisting of average droplets of D32 below $30 \mu \mathrm{m}$, capable of producing a spray that will readily absorb heat in the flame, without relying on further droplet breakup (or secondary atomization).

The SRA was ideally suited for the purpose of these investigations as the atomizer was capable of providing the required drop size of D32 below $30 \mu \mathrm{m}$ and was additionally modified with respect to flow rate, liquid volume flux and spray cone angle by reconfiguration of some of the interchangeable components, as shown below in Figure 1. 


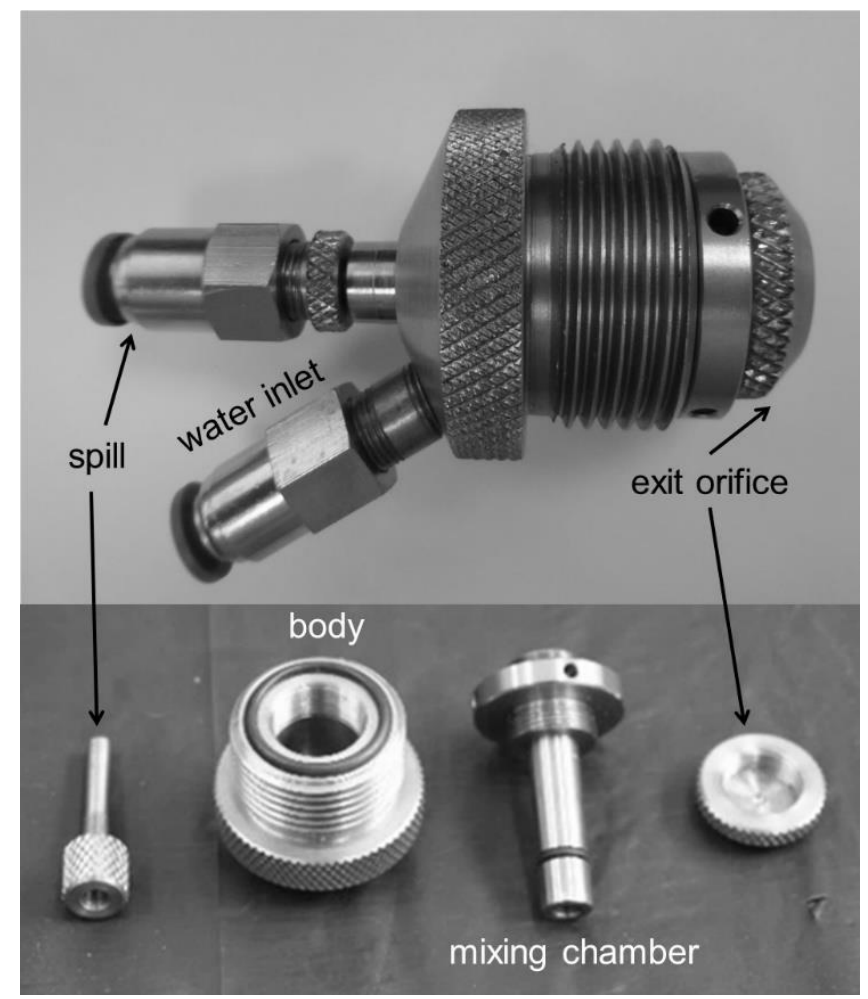

Figure 1: Assembled and component parts of SRA

SRAs were utilised previously for decontamination sprays in health setting for Methicillinresistant Staphylococcus aureus (MRSA). Further applications also include decontamination showers following a chemical or nuclear attack as well as within a helicoil arrangement and remote operated vehicle (ROV) for suppressing jet fires in oil and gas industry. It is also important to use SRAs to mitigate propagating combustion waves (or explosion) in oil and gas sites where there are congested pipe arrays.

In current investigation, however, Four SRA configurations were developed by replacing or modifying the exit orifice diameters. For clarity and ease of further reference, the atomizer arrangements were designated as Type A, B, C and D for identification throughout this study and are shown in Table 2 below. 
Table 2: Critical orifice diameters of different types of SRA

\begin{tabular}{|c|c|c|c|c|}
\hline & Type A & Type B & Type C & Type D \\
\hline Exit Orifice, $\mathrm{d}_{\mathrm{o}}(\mathrm{mm})$ & 0.3 & 0.5 & 0.8 & 1.0 \\
\hline Spill Orifice, $\mathrm{d}_{\mathrm{s}}(\mathrm{mm})$ & 0.5 & 0.5 & 0.5 & 0.5 \\
\hline Inlet Orifices, $\mathrm{d}_{\mathrm{i}}(\mathrm{mm})$ & $2 \times 0.6$ & $2 \times 0.6$ & $2 \times 0.6$ & $2 \times 0.6$ \\
\hline
\end{tabular}

The following objectives describe the challenges and advances required to progress the existing SRA technology and thus to be aligned to the present application.

i. To study the development of the existing SRA and to understand the fundamental concepts of operation.

ii. To characterize the sprays in open ambient conditions and within the simulated Polymethyl-Methacrylate (PMMA) tube (drop size, droplet velocity and mass flux) using PDA techniques.

iii. To increase the flux density and water volume fraction, without compromising the mean droplet sizes produced by the SRA.

iv. To produce a spray envelope containing a sufficient quantity of droplets that are small enough to reach boiling point and begin to vaporize within the flame.

v. To increase droplet 'residence time' in the flame front, thus permitting greater heat transfer.

vi. To produce suitable quality imaging i.e. still, HD video and high-speed video within the confines of the explosion and mitigation tube (see Figure 2). 


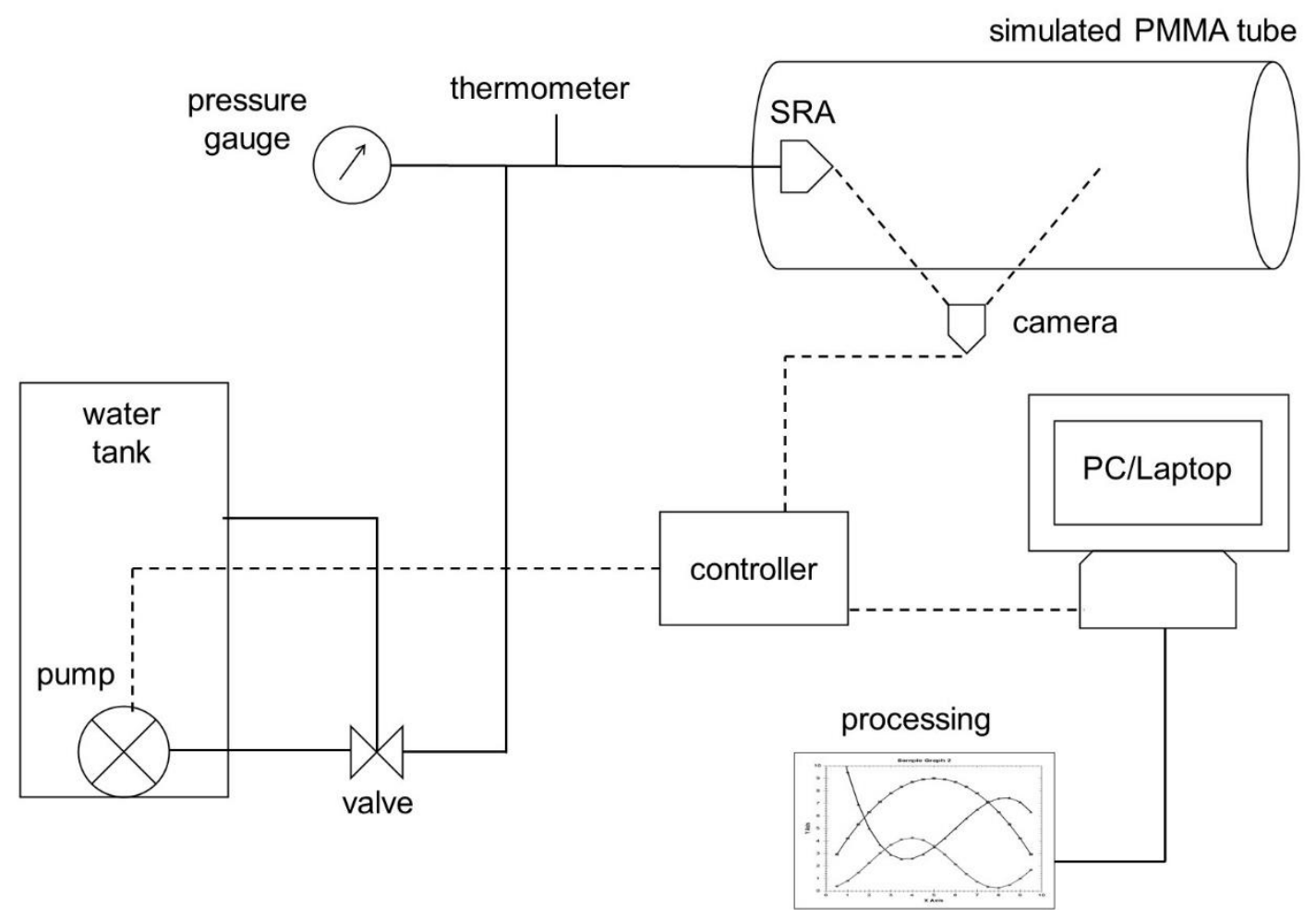

Figure 2: Schematic diagram of "cold trials": apparatus and setup

To achieve the objectives described above, a series of experiments, as described below, were applied to characterize the four SRA configurations.

i. Volumetric flow rate (see Section 2.1)

ii. $\quad$ SRA spray cone angle (see Section 2.2)

iii. Spray characterization in ambient and simulated condition within PMMA using PDA (see Section 2.3)

\subsection{Volumetric Flow Rate}

A series of volumetric flow rate trials were conducted to provide systematic flow rate data for the four single atomizer configurations, Type A, B, C and D, as well as comparing related previous data with present atomizer configurations. Each of the atomizers were evaluated by subjecting them to a range of pressures from 5 to $14 \mathrm{MPa}$. A test rig was designed and 
constructed to carry out the flow rate trials. The apparatus shown in Figure 3 consisted of a mounting frame, calibrated pressure gauge, atomizer mounting connections and spray convergence passage. Due to the fine droplets and aerosols corresponding to the SRA spray, the SRA was connected to a convoluted conical tube, referred to here as the 'spray convergence passage'. This device conveniently allowed the droplets and mist to coalesce, thus producing a reliable flow of water from its exit.

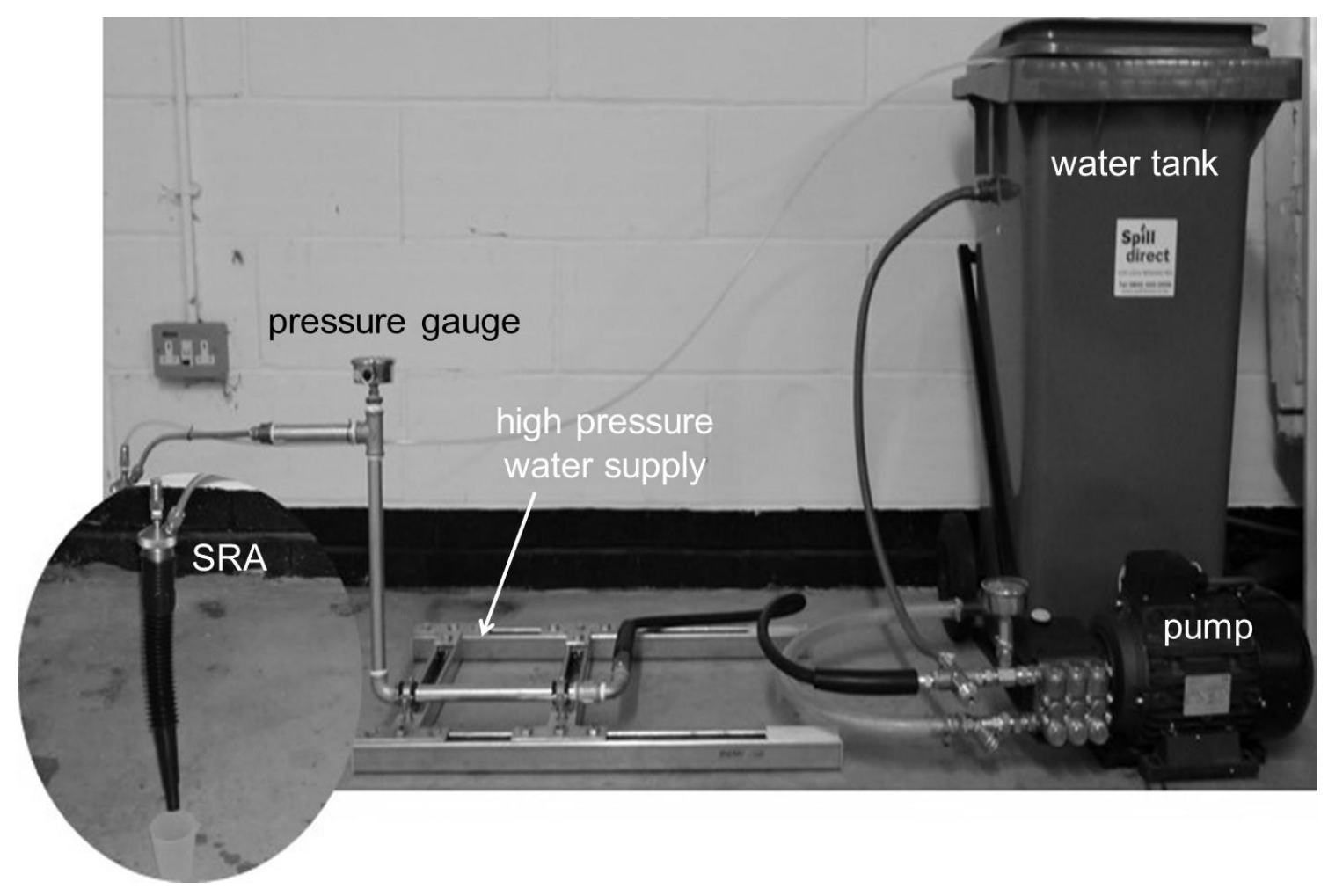

Figure 3: Test rig for volumetric flow rate

\subsection{Spray Cone Angle}

The importance of the spray cone angle varies with different studies and applications. In this present study it was important that the spray envelope should completely fill the internal cross section of the $190 \mathrm{~mm}$ PMMA tube of the FPMR. The individual atomizer configurations were installed in the test rig shown in Figure 4 and were supplied with de-ionized water at a pressure of $13 \mathrm{MPa}$. The spray cone angle measured by using the Adobe software. 


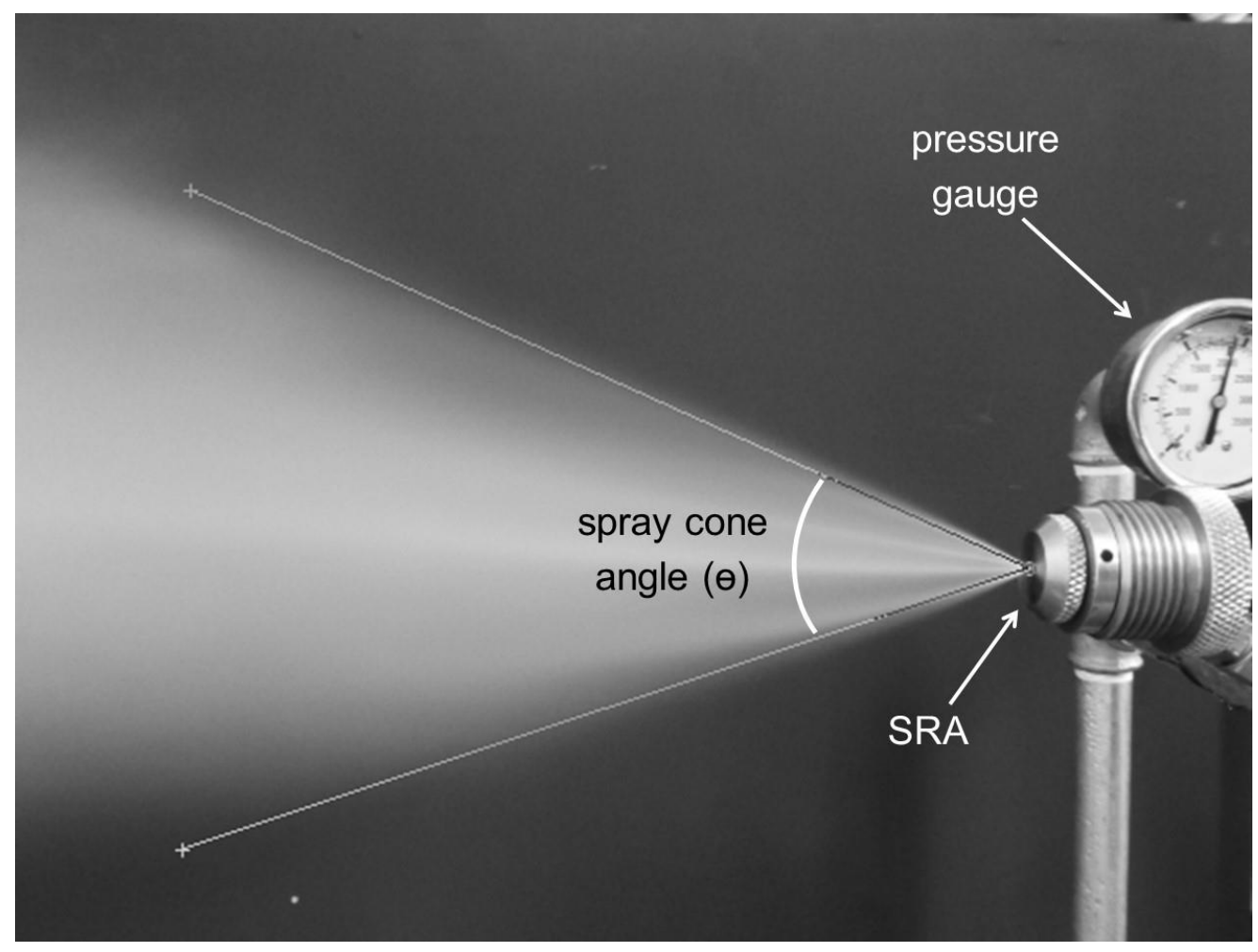

Figure 4: Typical spray cone angle measurement

\subsection{Spray Characterization using Phase Doppler Anemometry (PDA)}

\subsubsection{Ambient Condition}

PDA apparatus used in this study to characterize the spray. In order to obtain radial positions throughout the flow, the atomizer was traversed horizontally using a mounting trolley relative to the beams with the transmission optics fixed, as shown in Figure 5. The radial positions were situated at 5 or $10 \mathrm{~mm}$ intervals from the centre of the atomizer orifice. A vertical traverse was constructed in order to record radial plots with each atomizer configuration at various downstream distances. 


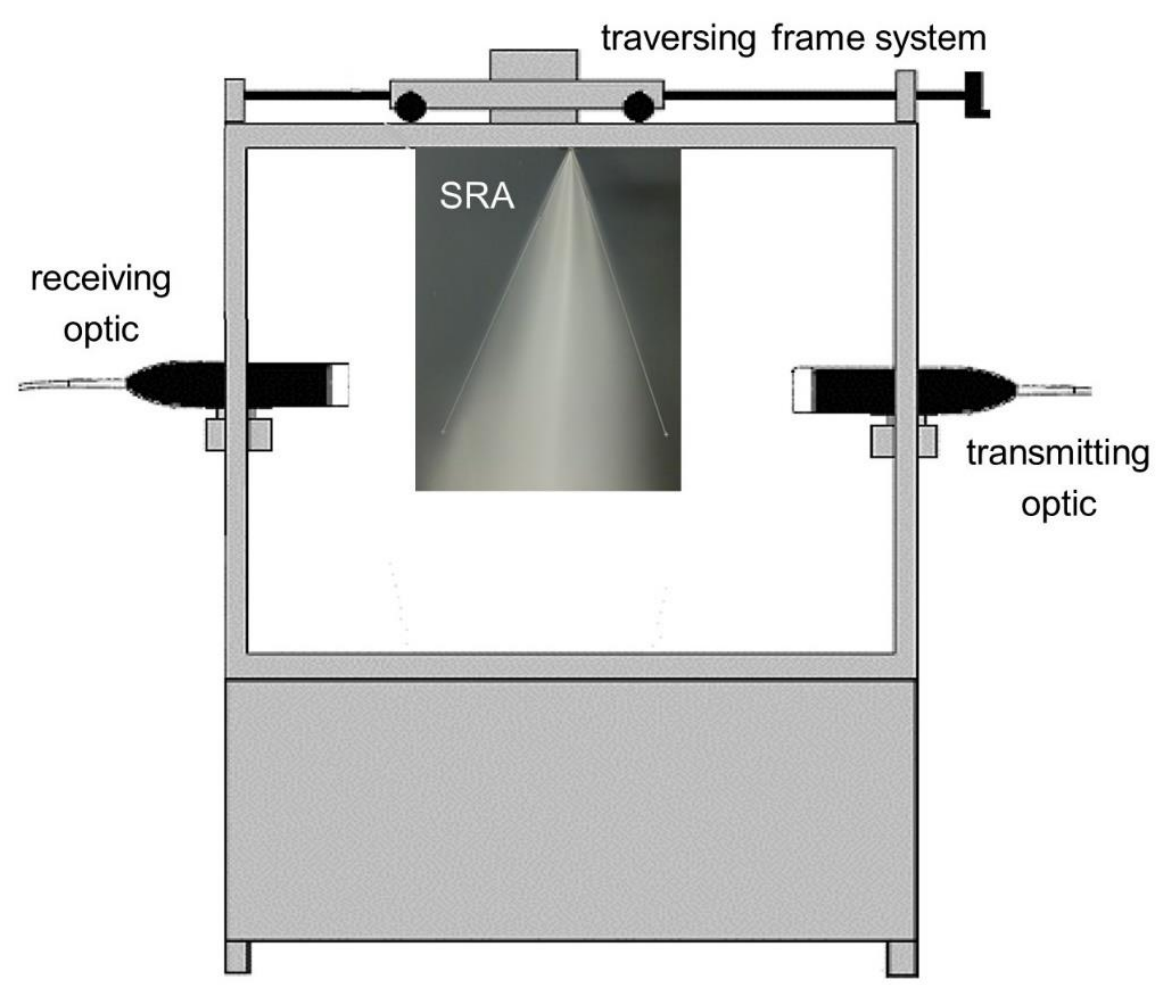

Figure 5: PDA setup for ambient condition

Previous studies by Nasr et al. (2011) considered measurements at various axial intervals downstream of the SRA up to and including $700 \mathrm{~mm}$. However, for this study there was a need to capture data axially from downstream position of $95 \mathrm{~mm}$, as illustrated in Figure 6 . This data point and spatial position was approximately the center of the spray when enclosed within a 190 mm PMMA tube of the FPMR. 


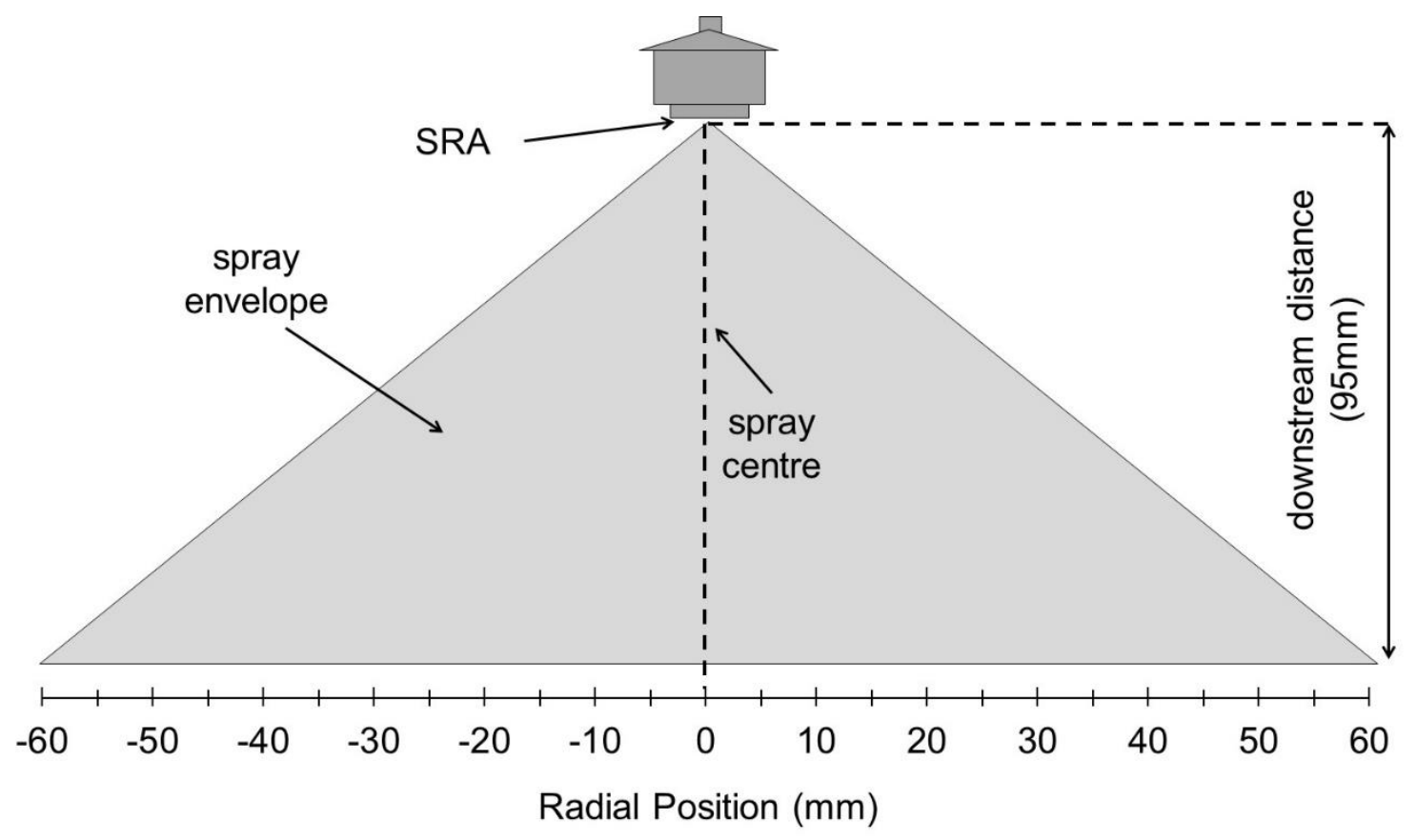

Figure 6: Axial and radial sampling positions

\subsubsection{Within Simulated PMMA Tube}

A new test rig was constructed within the existing PDA and traversing system as shown in Figure 7, which facilitated the mounting of a short section of PMMA tube with $190 \mathrm{~mm}$ internal diameter. Although the PMMA tube was coated liberally with hydrophobic spray, the main challenge in obtaining data was the build-up of water droplets on the inside surface of the tube as shown inf Figure 8. Initial trials produced highly irregular results whereby many cases resulted in trials being aborted due to the receiving optics not being able detect droplets in the measuring volume. A consequence of the deposition and coalescence of water droplets on the inner surface of the PMMA tube resulted in the laser beams exiting the transmitting optics being refracted and diverted. Additionally, although the outer surface of the PMMA tube was coated with anti-reflective matte spray, the shiny surface was also detrimental to data acquisition. 


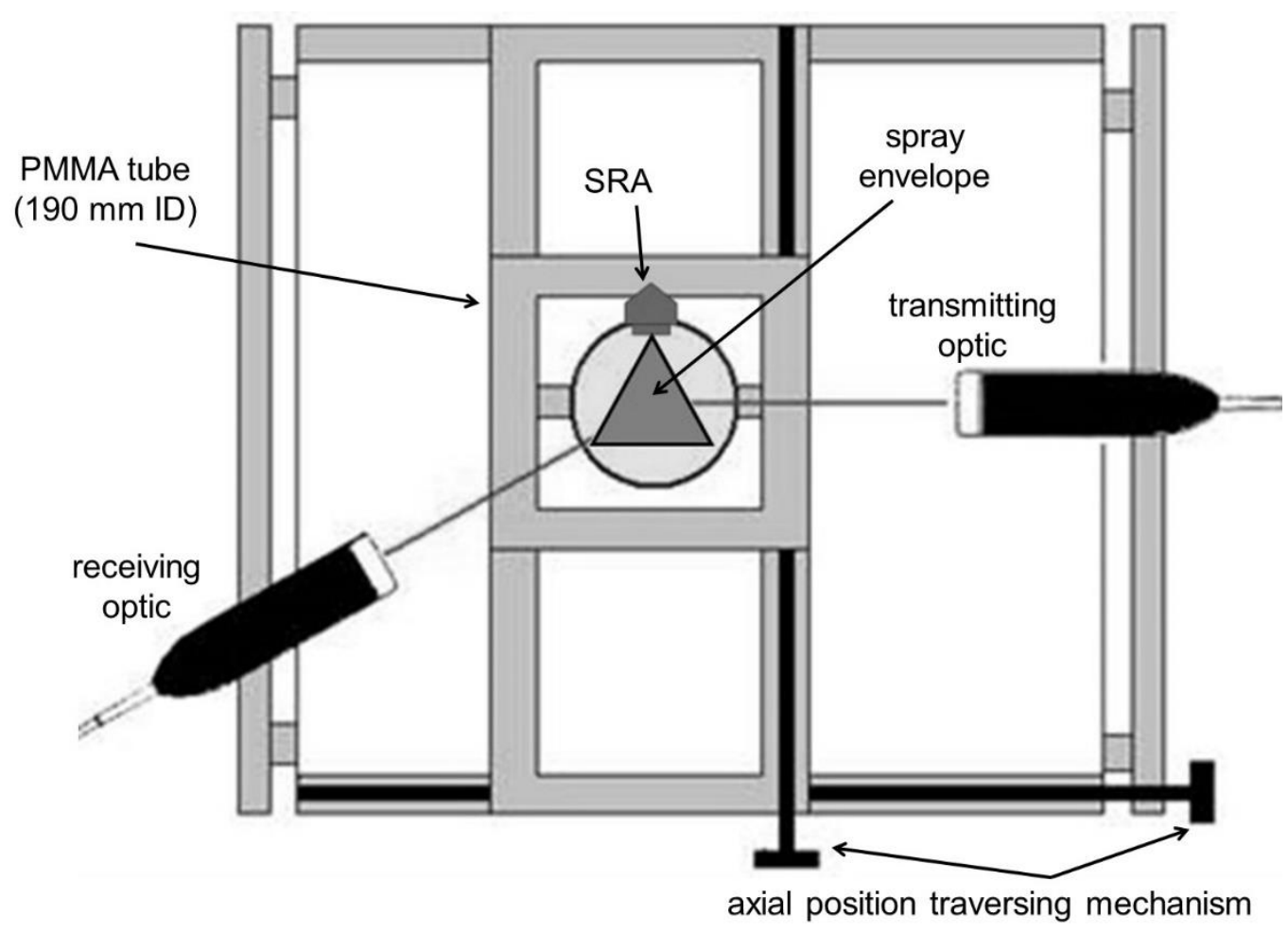

Figure 7: Schematic diagram of setup for the PMMA tube: SRA position and PDA optics

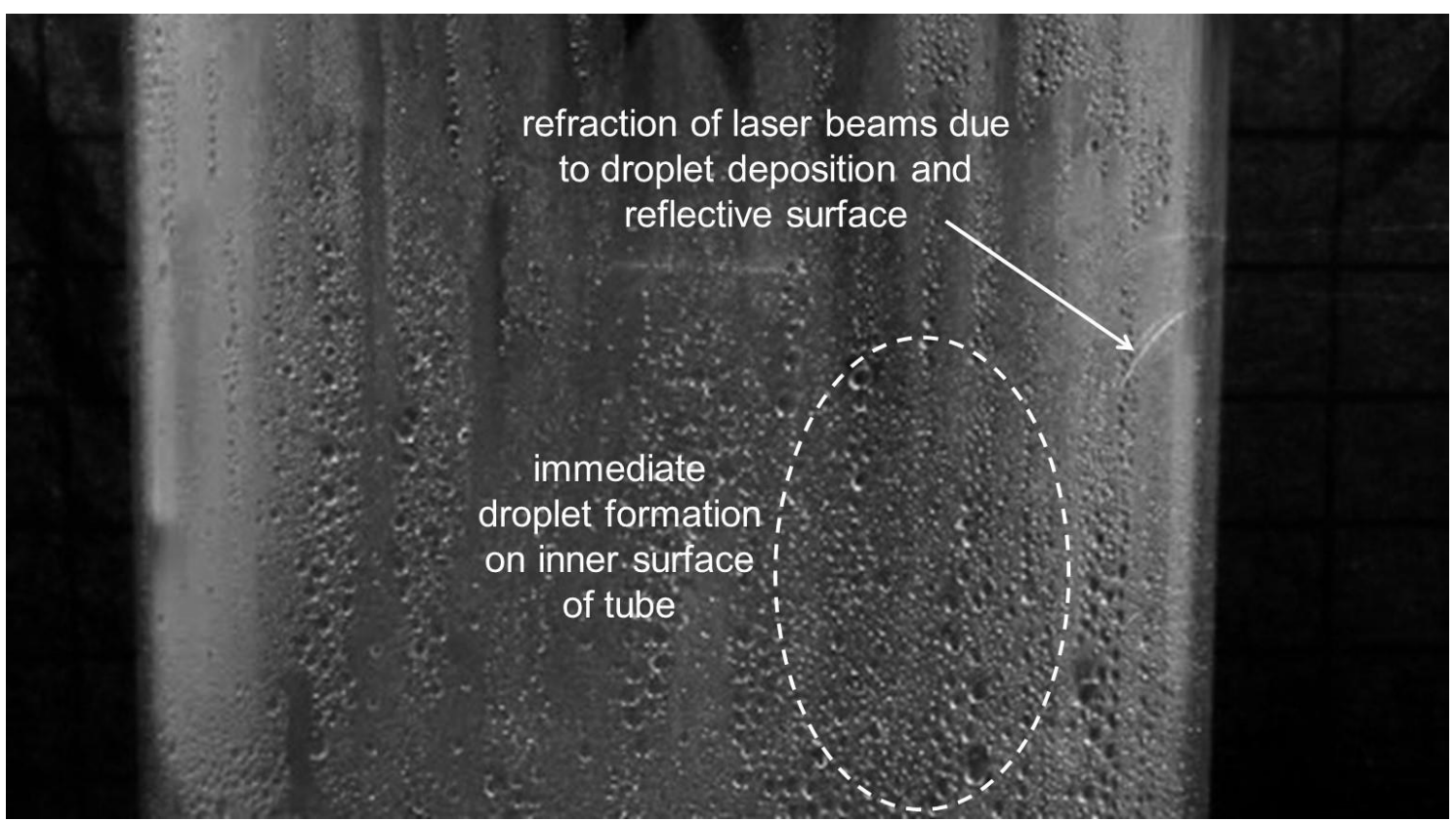

Figure 8: Droplet deposition and refraction of laser beams in simulated tube 
The equipment shown in Figure 7 was refined through experimental trials and eventually a successive series of tests were performed with a consistent level of success. As illustrates in Figure 9, two slots were cut on opposite sides of the PMMA tube to provide line of site for the transmitting and receiving optics. Additionally, a wet and dry vacuum was placed near to the receiving optics slot to reduce the misting of the lens caused by the aerosols in the spray.

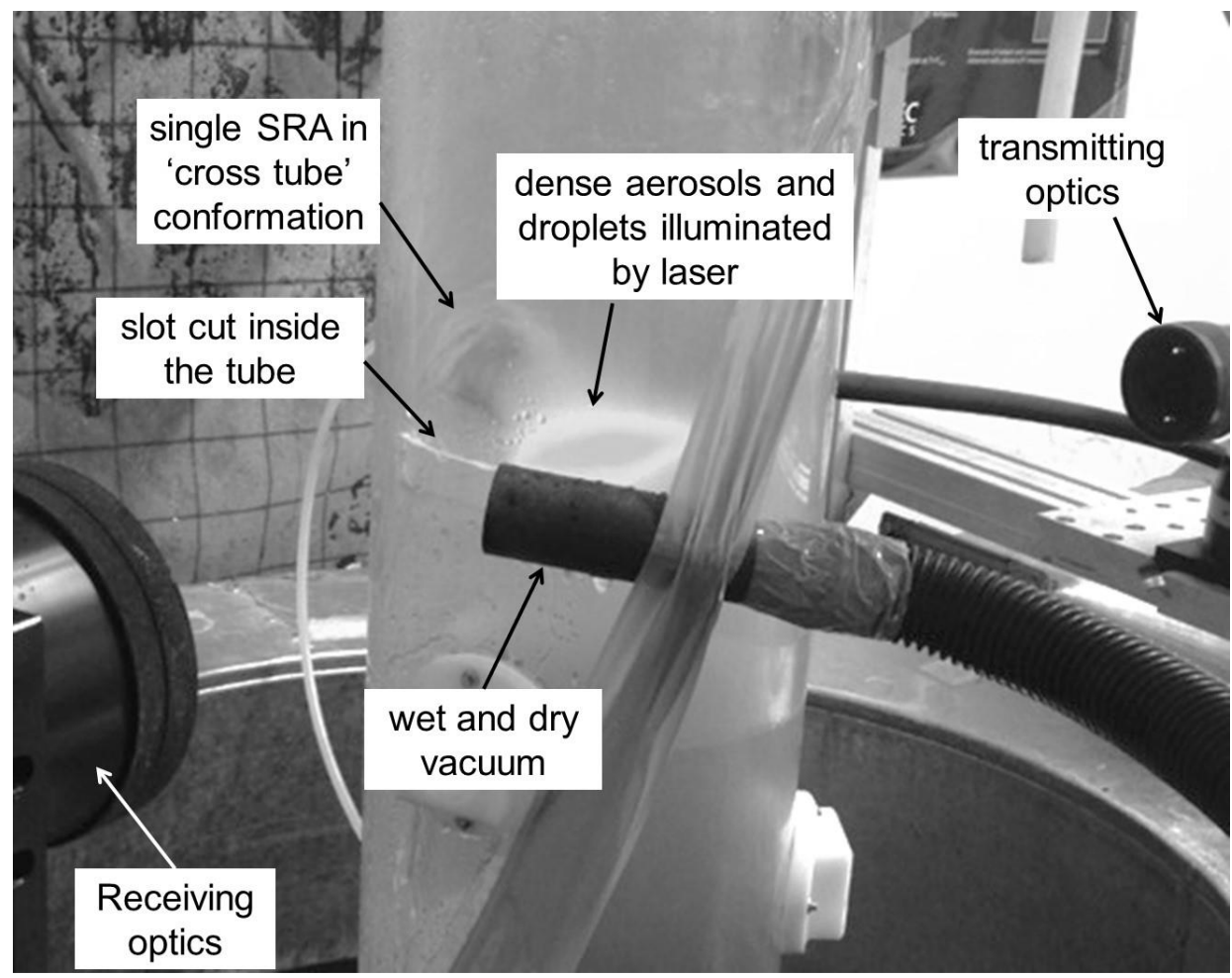

Figure 9: Set up to acquire data for enclosed single SRA cross spray conditions

\section{Results and Discussions}

\subsection{Volumetric Flow Rate}

Figure 10 shows the throughput consistency of each of the atomizers over a range of typical operating pressures. The SRA configurations Type A, B and C can be seen to exhibit typical linear relationships between pressure and flow in both the exit and spill diameters. Whereas, the Type D SRA only produced consistent linear results at the exit orifice. The spill diameter 
flow rates were found to be non-uniform, and this was coupled with an erratic, spluttering stream from the spill tube.
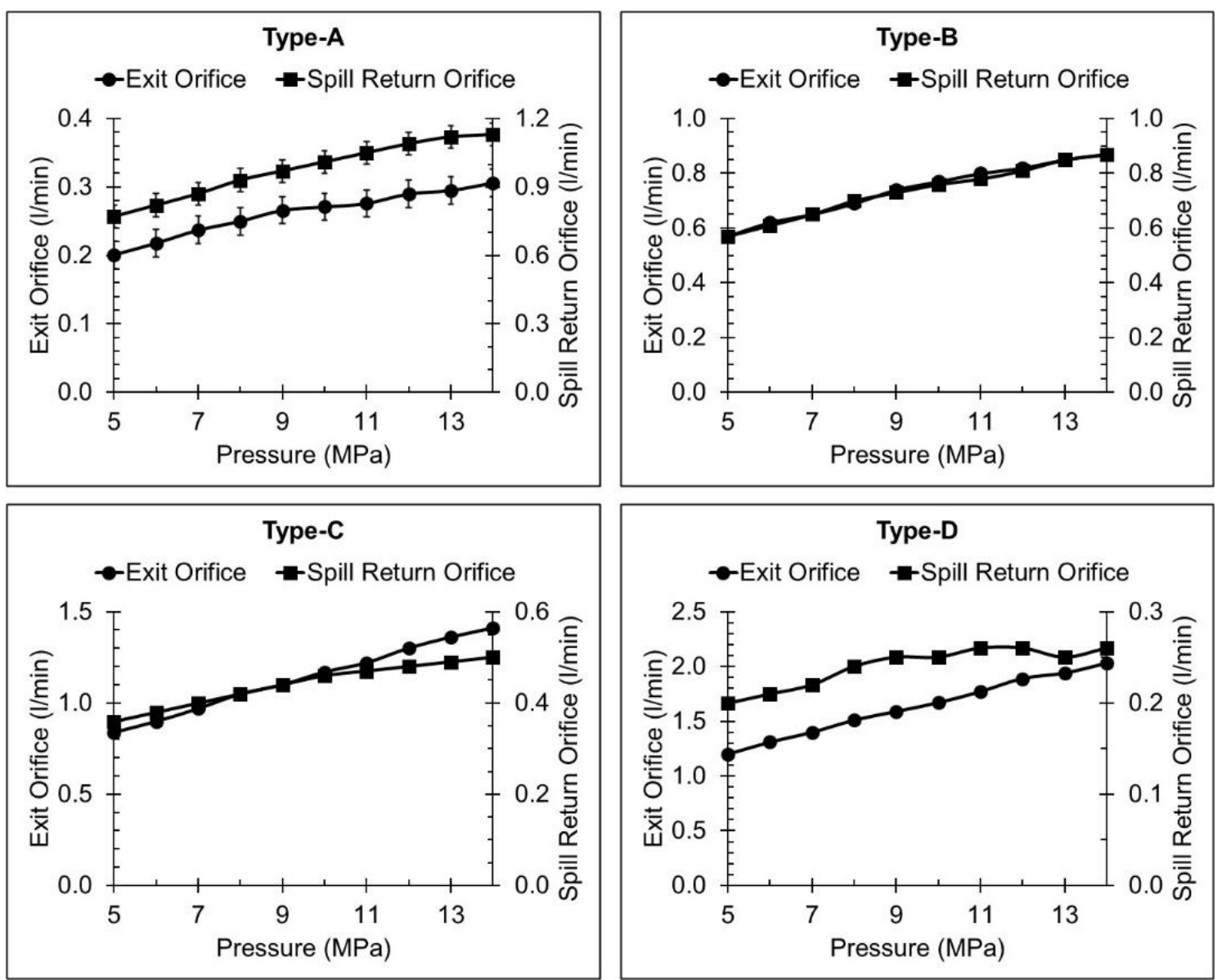

Figure 10: Typical flow rates for different types of SRA at different pressure

A second series of tests were conducted using the Type D SRA to validate the apparent inconsistency, whereby the results were found to be in agreement with the original data that has been presented. The inconsistencies found in the spill flow rates of configuration Type D have been attributed to the flow rate limitations in the swirl chamber of original design of the SRA.

The irregularities associated with the SRA Type D configuration subsequently resulted in removing the atomizer from the selection list of potential atomizer configurations for next 
phase of this study called "hot trials" with different fuel-air mixture. However, this atomizer was used in some experiments for comparison purposes (i.e. cone angle measurement) during "cold trials".

\subsection{Spray Cone Angle}

Figure 11 shows the spray cone angle measurements for all four SRA configurations. The importance of the spray cone angle varies with different studies and applications. As explained before, in this present study, it was important that the spray envelope should fill the internal cross section of the $190 \mathrm{~mm}$ PMMA tube for the purposes of hot flame mitigation.
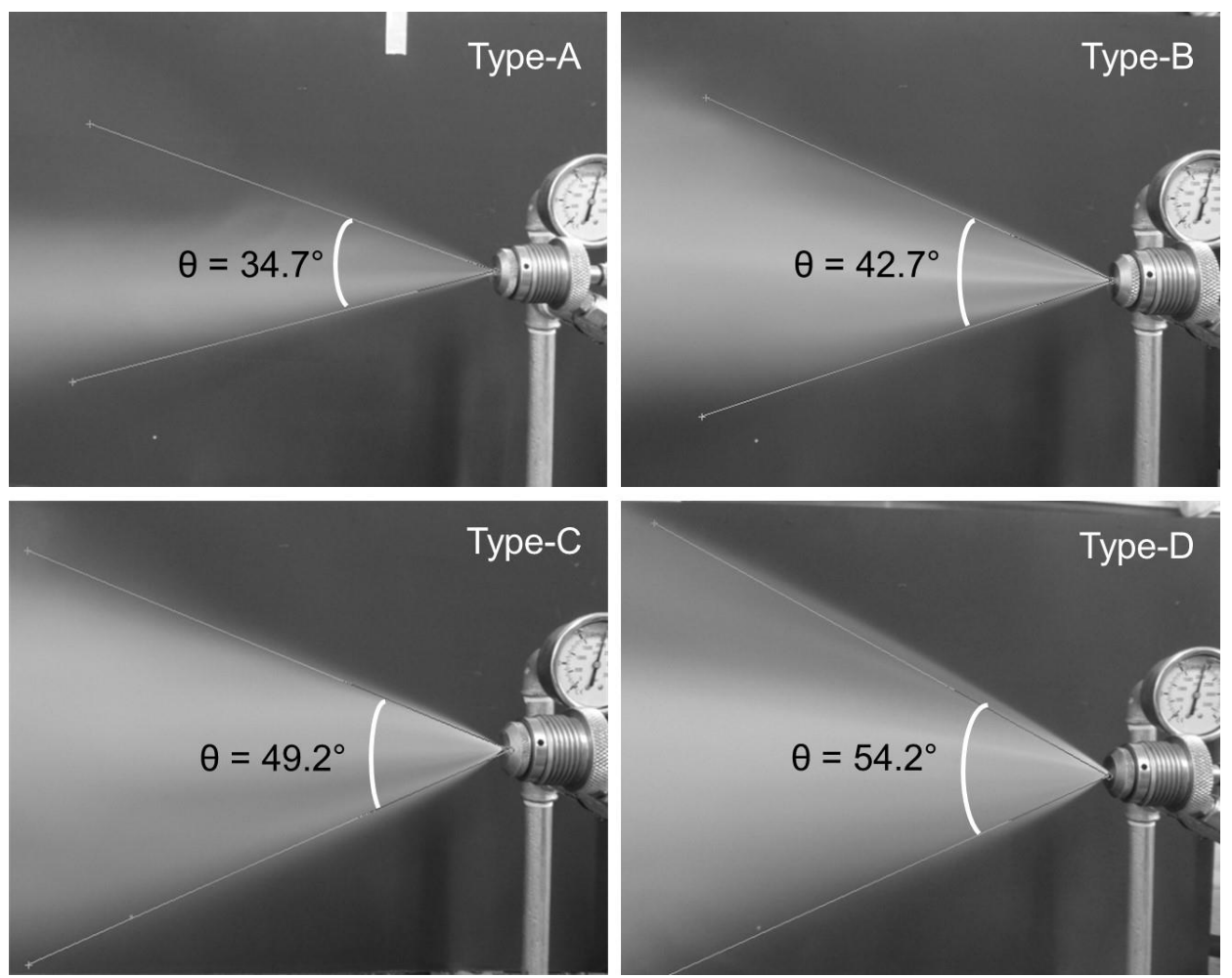

Figure 11: Spray angle for different SRA types

\subsection{Spray Characterization Using Phase Doppler Anemometry (PDA)}

\subsubsection{Ambient Condition}


A previous publication by Nasr et al. (2011) produced data for a single SRA spray in ambient conditions with $0.3 \mathrm{~mm}$ exit orifice (tip) and $0.5 \mathrm{~mm}$ spill return orifice, known as the SRA 'Type A' in this present study. These results were obtained using the same PDA apparatus and traversing frame system as used in previous studies (Nasr et al., 2011, Stewart, 2011). It may be assumed that the accuracy and sources of error in the previous reported work approximates those encountered in this current study. The results presented in the following are discussed with relevance to this current study and are used, where appropriate, from the previous decontamination study (Nasr et al., 2011), mostly for comparative analysis.

The atomizer selection process within this study requires that a spray is formed which contains a suitable number of droplets, of a small enough diameter $(\mathrm{D} 32 \leq 30 \mu \mathrm{m})$ to extract heat from the flame front, within the finitely short time $(\leq 0.03 \mathrm{~ms})$ afforded as the droplets traverse the flame front and reaction zone ( 1 mm thickness). To achieve this, previous studies (Sapko et al., 1977) have postulated that water droplets of $18 \mu \mathrm{m}$ would just reach boiling point within a $1 \mathrm{~mm}$ thick flame front, in a stoichiometric methane-air mixture travelling at $2.3 \mathrm{~m} / \mathrm{s}$. Recent mathematical (Van Wingerden and Wilkins, 1995, Van Wingerden et al., 1995) and CFD studies (Kasmani et al., 2006) are in agreement with these original claims (Sapko et al., 1977). Moreover, the higher the frequency of droplets, that are small enough to vaporize in the spray, the greater the heat transfer from flame to droplet owing to the release of the latent heat of vaporization. From the previous study by Sapko et al. (1977), the ratio of droplets within the range of $\leq 18 \mu \mathrm{m}$ and $>18 \mu \mathrm{m}$ may be considered as an estimate of the ratio of heat transfer by latent heat.

In the previous study (Nasr et al., 2011) single SRA sprays were characterized at various downstream distances across the radial axis of the spray using PDA, however as mentioned above, although some data was available for the SRA with $0.5 \mathrm{~mm}$ exit orifice and $0.5 \mathrm{~mm}$ spill diameter from previous work (Stewart, 2011, Nasr et al., 2011), known as the SRA Type 
B, there was a need in this present study, to capture further data axially from downstream position of $95 \mathrm{~mm}$, as illustrated in Figure 6 . This data could then be analysed and compared to the same spatial position, approximately the centre of the spray when the spray was enclosed within a 190 mm PMMA tube.

Figure 12(a) has been produced using the data acquisition from the new characterization of the Type B SRA in ambient conditions at a downstream position of $95 \mathrm{~mm}$. As it illustrates the D32 of the spray at various radial positions. The mean diameter of the spray was found to have a D32 of $26 \mu \mathrm{m}$, which is consistent with the previous study. Although this mean diameter is slightly larger than the $\leq 18 \mu \mathrm{m}$ suggested by Sapko et al (1977) for a $1 \mathrm{~mm}$ thick flame front, the droplet distribution indicates a large percentage of droplets that are $\leq 30 \mu \mathrm{m}$, in line with the principle objectives of this current study.

The droplet velocity profile offered in Figure 12(b) is consistent with the velocity profile from the previous study by Nasr et al (2011) and shown in this Figure. The mean radial droplet velocity was estimated to be $21.41 \mathrm{~m} / \mathrm{s}$ and will be used for analysis and conclusions in the "hot trials" results and discussions. The liquid volume flux is also shown in Figure 12(c). The results presented in this Section are in agreement with the previous study (Stewart, 2011) and demonstrate a high level of repeatability and therefore confirm the reliability of the set up used in these present investigations. 

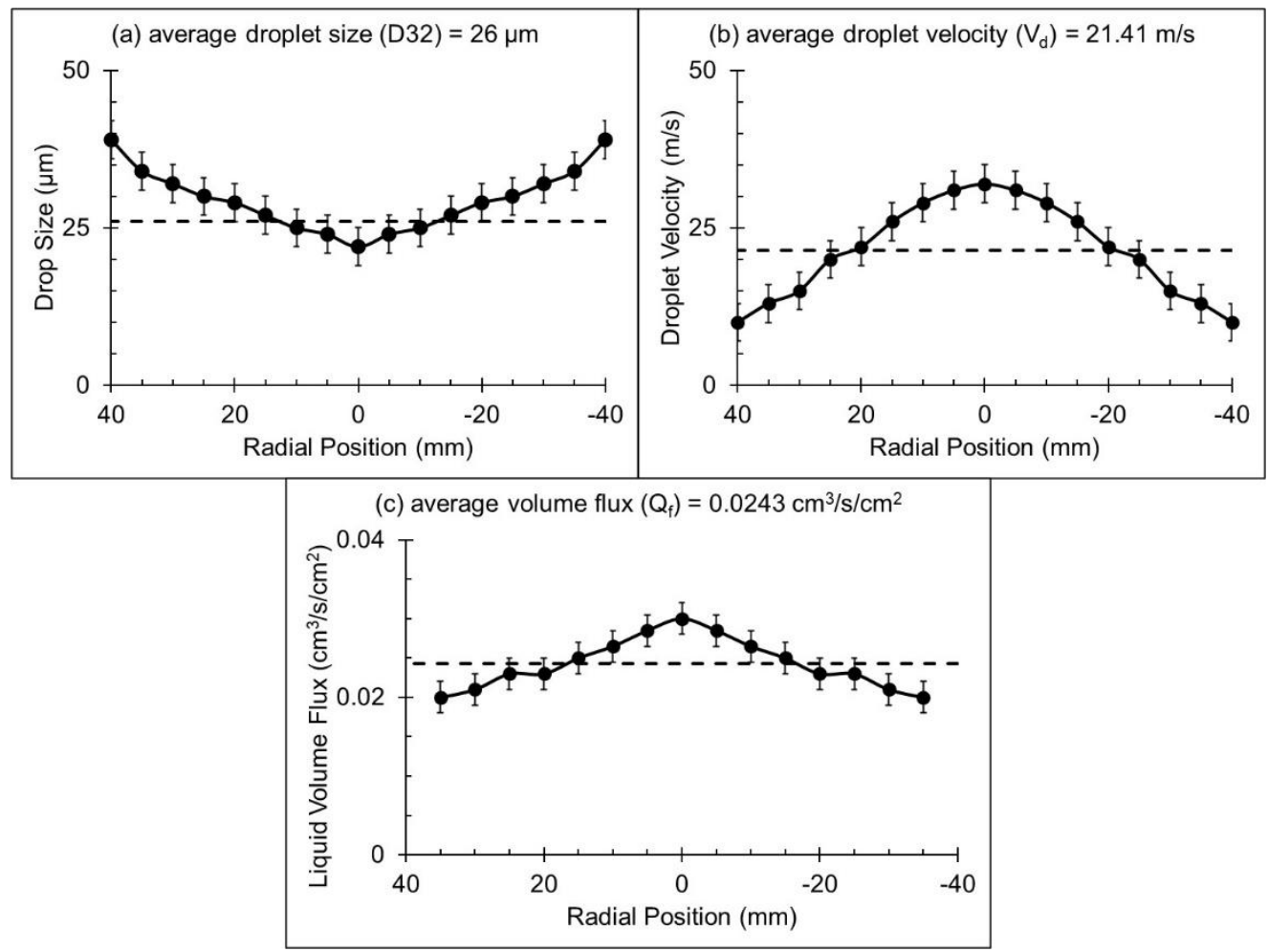

Figure 12: Spray characterization of SRA Type B at various radial position

The single SRA configuration Type $\mathrm{C}$ was developed by the author for this current study to provide a larger spray cone angle with resulting spray envelope, to be used within the enclosed conditions of the FPMR. Figures 13(a) and 13(b) have been produced using the data obtained from the new characterization of the SRA type $\mathrm{C}$ in ambient conditions, at a downstream position of $95 \mathrm{~mm}$. 


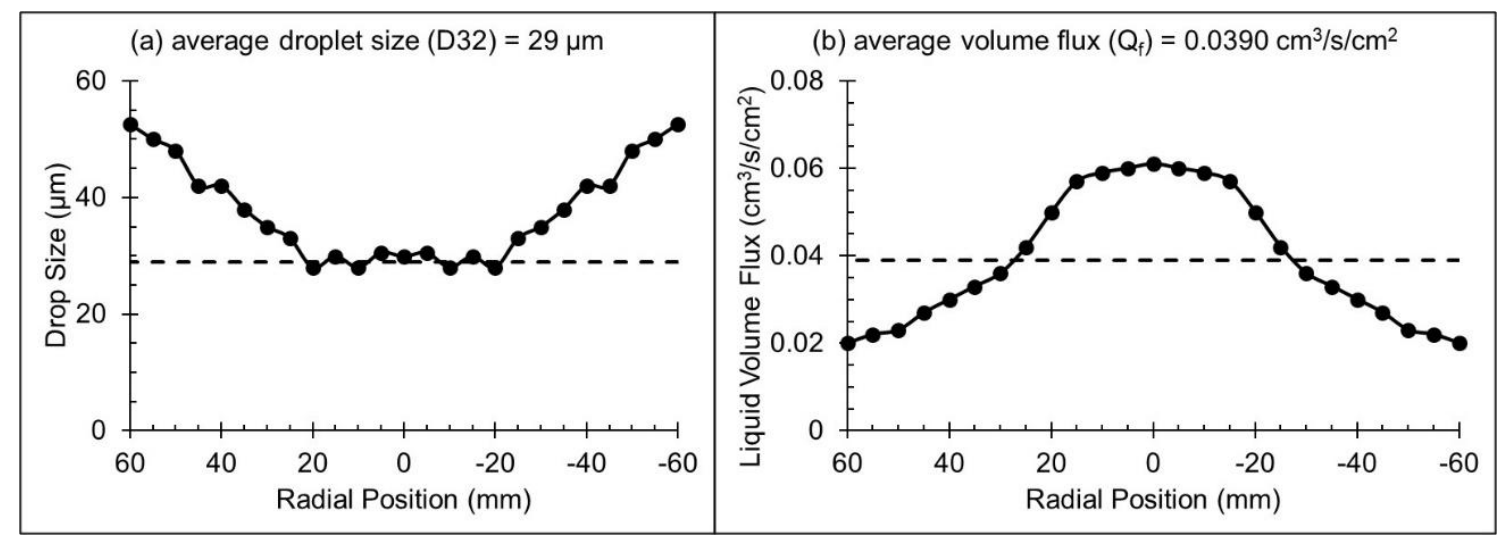

Figure 13: Spray characterization of SRA Type $C$ at various radial position

As shown in Figure 13(a), the average radial D32 droplet size of SRA Type C was estimated to be $29 \mu \mathrm{m}$ which coincides with the principle objective of this current work with D32 $\leq 30$ $\mu \mathrm{m}$.

In addition to the use of single SRA configurations, an 'in-tube' manifold array was developed whereby two SRA Type B could be securely mounted and operated in counter or parallel flow, within the FPMR. The manifold was fabricated using 316 stainless steel tube and is referred to as the 'multiple overlap' atomizer manifold. Figure 14 illustrates the main components of the 'multiple overlap' SRA. Subsequent to the completion of individual spray characteristics in ambient conditions, the sprays from the multiple overlap atomizers also needed to be appraised using PDA, prior to "hot trial" testing in the FPMR to assess to potential effects of spray overlap. 


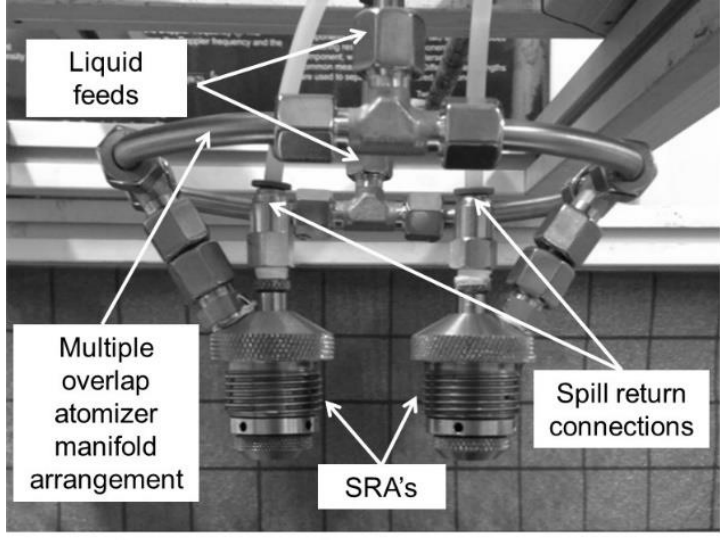

(a) Atomizer manifold with two SRA Type-B

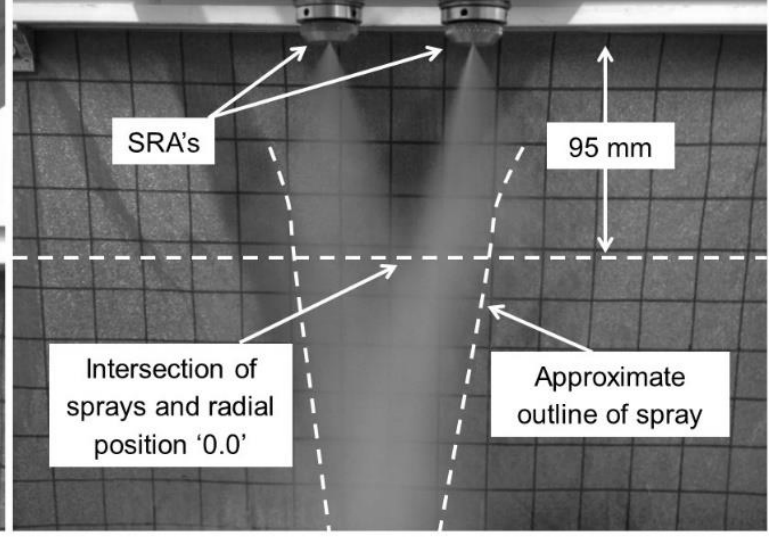

(b) Spray Overlap

Figure 14: Setup for Multiple Overlap Spray of SRA Type B

The multiple overlap atomizer manifold was attached to the traversing frame system and the PDA shown previously in Figure 5. The atomizers were supplied with de-ionized water at a pressure of $13 \mathrm{MPa}$ and were adjusted to deliver overlapping sprays that intersected $95 \mathrm{~mm}$ downstream of the exit orifices. This intersection point is defined as the radial position ' 0.0 ' as shown in Figure 14(b). The distance of $95 \mathrm{~mm}$ has been applied in all "cold trials" and is consistent with all experiments carried out in the study, thus approximating the central position of the spray within the confines of the PMMA tube. Figure 14(b) shows qualitatively the spray image of the multiple overlap atomizer arrangement. A significant amount of entrainment was occurring, this was instigated by the interaction of the sprays and also subsequent coalescence of droplets at the point of intersection and immediately downstream of the sample axis. This is reinforced and discussed in the following corresponding data.

The subject of overlapping sprays has been examined and modelled by several authors. Kaesemann and Fahlenkamp (2002) derived a computational model for sprays used in a flue gas scrubber. In all cases there was a higher droplet concentration reported in the overlapping region, coupled with an increase in D32 due to the collision and coalescence of droplets. In certain fire suppression or explosion mitigation situations overlapping sprays will provide an advantage, such as: 
- In a fire curtain or deluge system consisting of multiple sprays, the larger droplets resulting from overlapping sprays will have a greater mass, thus increasing the likelihood of the droplets overcoming thermal up draught currents from the fire and therefore allowing the water droplets to reach the seat of the fire and to cool the solid fuel material.

- In high speed flame propagation and mitigation experiments, larger droplets are used because of their ideal Weber number and hydrodynamic instability. Many of the studies previous studies (Sapko et al., 1977) utilized overlapping sprays.

However, the consequential increase in D32 from overlapping sprays is unlikely to be an advantage in this current work, as droplet heating and vaporization within the flame front is the principle mechanism of heat transfer. Whereas in previous studies using accelerated flames, droplets were broken up by the force of the blast into ultrafine mist.

The D32 of the multiple overlapping Type B atomizers was found to be in a range from approximately 35 to $45 \mu \mathrm{m}$ at the centre of the spray, rising to $54 \mu \mathrm{m}$ at a radial position of 50 mm, as shown in Figure 15(a). A significant increase in drop size was also observed towards the extreme limits of the spray. These were probably droplets that had gained sufficient mass, so as not to be entrained with the smaller droplets. This is reinforced in Figure 15(a), where only a very small number of droplets were found between 70 to $80 \mu \mathrm{m}$.

As anticipated, droplet velocity and liquid volume flux are highly irregular across the sample and this is reinforced by the representations in Figures 15(b) and 15(c). The velocity is initially slow in the centre of the sprays at the point of overlap. This negative droplet velocity is an indication that droplets were travelling in the opposing direction and are attributed to the 
recirculating eddies in the extremities of the spray caused by the air entrainment. This is not apparent in Figure 15(c), as droplet direction or trajectory will not affect liquid volume flux.

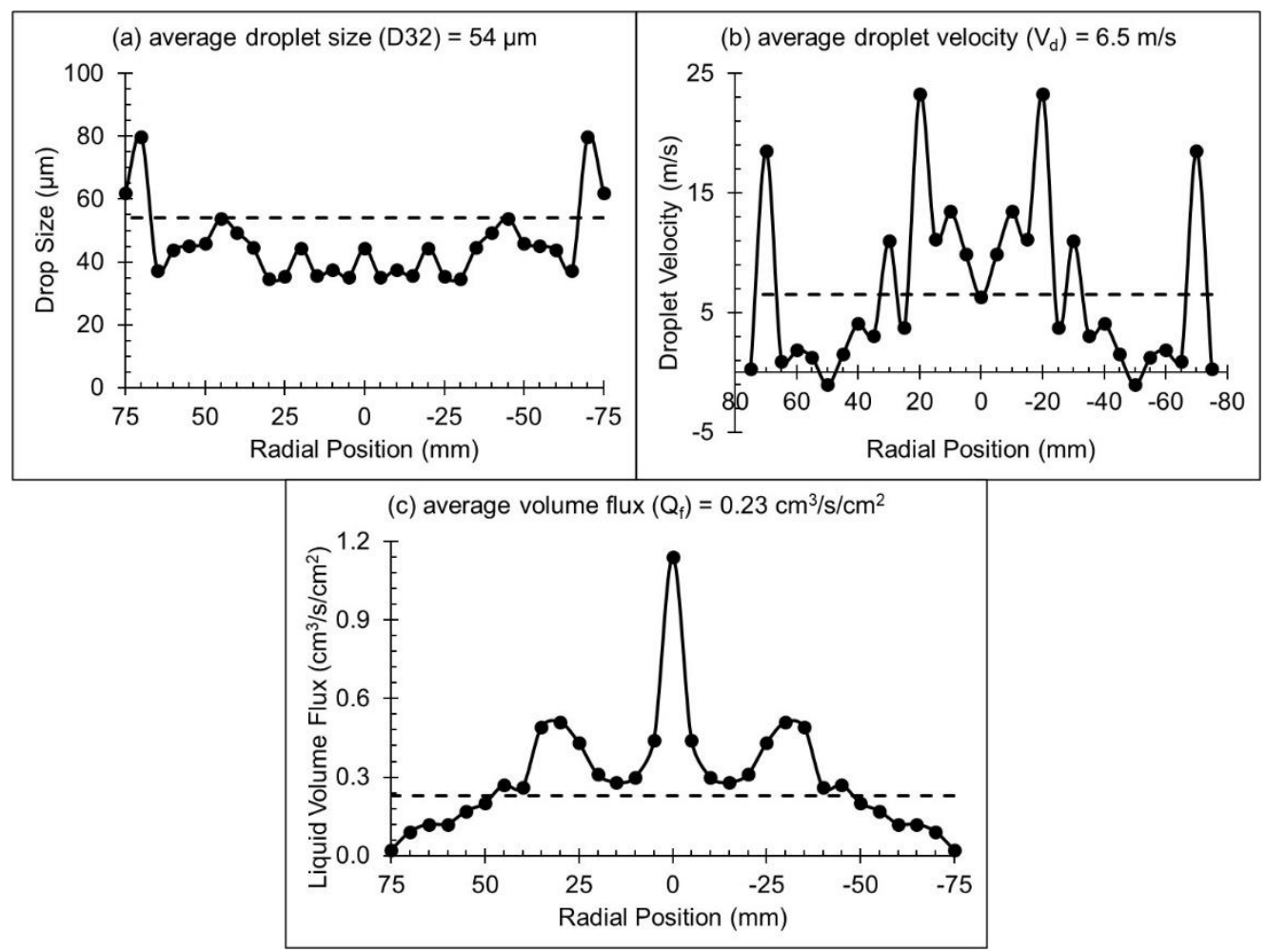

Figure 15: Spray characterization of multiple SRA Type B at various radial position

\subsubsection{Within Simulated PMMA Tube}

To ensure that valid and reliable conclusions could be derived from the "hot trials", additional spray characterization was necessary to assess the behaviour of the sprays within the FPMR. Throughout all previous studies it is evident that there was no evidence that this was either carried out or considered. Consequently, the inclusion of this additional testing will reinforce the reliability of the reported evidence in the "hot trials". Conversely, the omission of such information in previous studies casts some doubt into the accuracy and degree of error in their reported findings. Initial trials produced highly irregular results, including many cases in which the experiment was aborted as the receiving optics could not detect the droplets in the measuring volume. 
The main challenge was the build-up of fine water droplets and aerosols on the inside surface of the tube. As shown previously in Figure 8, the laser beam from the transmitting optics being refracted by the external surface of the tube and by the droplet deposition on the inside of the tube. An alternative method was required to capture the droplets within the tube, with a clear 'line of sight' for the transmitting and receiving optics. The equipment shown in Figure 9 was refined through experimental trials and eventually an uninterrupted series of tests were performed with a consistent level of success.

The atomizer arrangements selected for the enclosed 'cross tube' characterization trials were SRA Type B and Type C. Although not all of the droplets in the spray were enabled to be captured, the results presented were all repeatable. This was due to the high degree of misting and pluming caused by aerosols within the tube, with the atomizers being in cross tube conformation. It is conceivable that limited secondary atomization would have been occurring, as the spray droplets impacted against the opposing internal surface of the tube. While deemed to be outside of the scope of this current study, additional spray research to attempt to quantify the aerosol sized droplets $(\leq 10 \mu \mathrm{m})$ would be beneficial for future work.

The single SRA Type B configuration was characterized in 'cross tube' spray confirmation using the additional set up shown previously in Figure 9. The D32 of the spray was found to be within the range of $30 \mu \mathrm{m}$ to $46 \mu \mathrm{m}$ across the radial axis, $95 \mathrm{~mm}$ downstream of the SRA exit orifice. This range was narrower than that found with the corresponding atomizer in ambient air. In addition, the D32 measured at the axial centre of the spray was found to be $30 \mu \mathrm{m}$ in this enclosed trial as shown in Figure 16(a), compared to $25 \mu \mathrm{m}$ in the ambient sample, as shown previously in Figure 12.

The most likely reason for this increase is that the droplets in the region of the sampling volume were gathering some mass from the droplets and mist returning in the opposite direction, resulting from the impact from the opposing internal surface of the tube. This postulation is 
supported by the velocity profile presented in Figure 16(b), which demonstrates a high level of disorder across the spray.

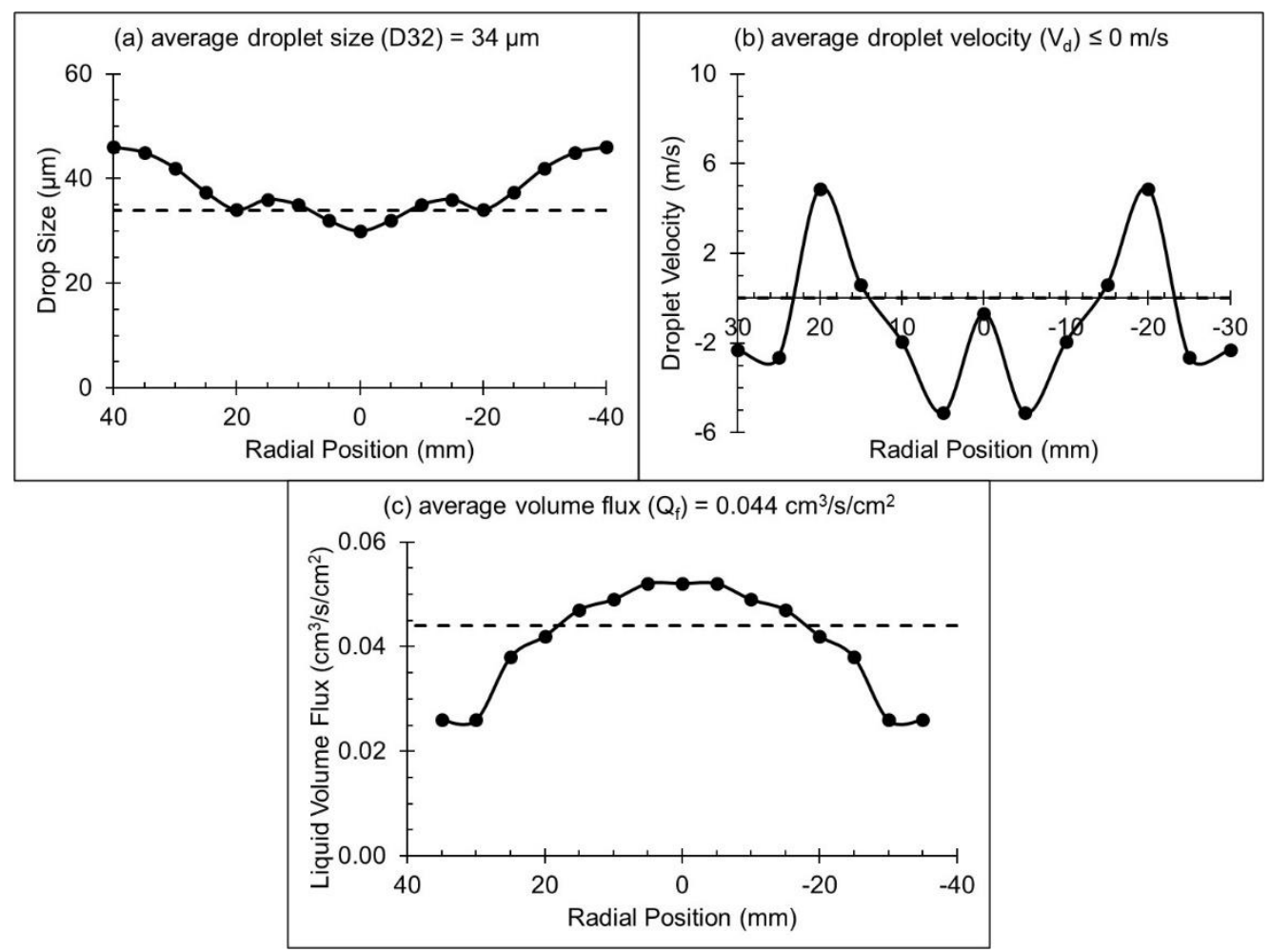

Figure 16: Spray characterization of SRA Type B within PMMA tube at various radial position

Additionally, the area of the graph below the $\mathrm{x}$-axis in Figure 16(b) is approximately equal to the area above the $x$-axis, which represents an average velocity of approximately $\leq 0 \mathrm{~m} / \mathrm{s}$. This 'mean suspension' of radial droplet activity provides for ideal conditions for droplet interaction with the approaching flame front. The liquid volume flux profile for this spray configuration is revealed in Figure 16(c), where values range from 0.02 to $0.8 \mathrm{~cm}^{3} / \mathrm{s} / \mathrm{cm}^{2}$, with a sample average of $0.044 \mathrm{~cm}^{3} / \mathrm{s} / \mathrm{cm}^{2}$.

In agreement with the results obtained from the enclosed condition trials for the SRA Type B, the enclosed SRA Type $\mathrm{C}$ also displayed an increase in droplet size and a dramatic reduction 
in velocity, when compared to ambient results previously presented previously. Figure 17(a) shows the D32 profile of the spray with drop sizes ranging from 34 to $51 \mu \mathrm{m}$ and with resulting average value of $39 \mu \mathrm{m}$.
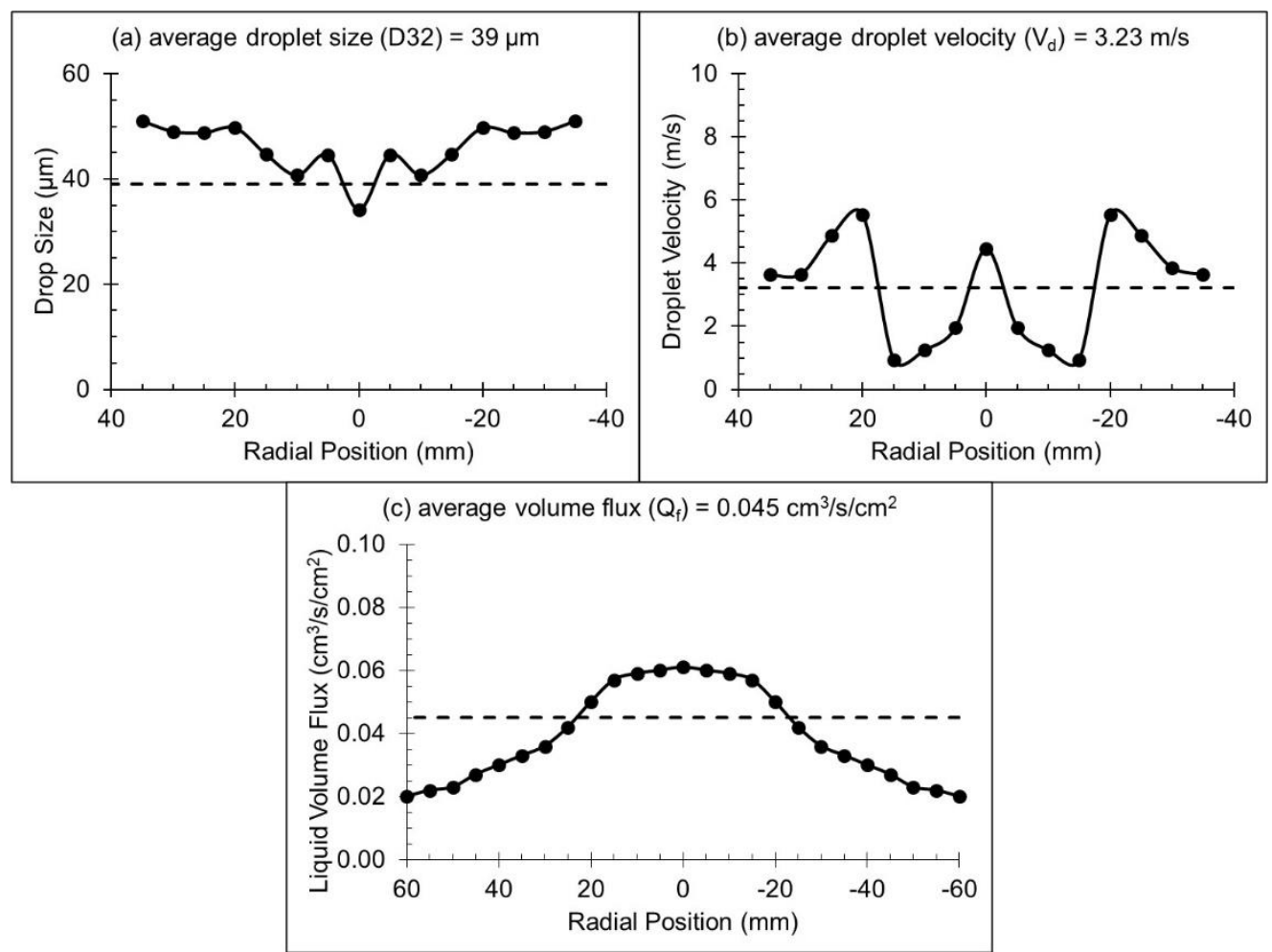

Figure 17: Spray characterization of SRA Type C within PMMA tube at various radial position

As with the observations concerning the enclosed conditions for the SRA Type B, the droplet velocity shown in Figure 17(b) is highly disorganized across the sample. This is due to droplet collision and consequential break up on the opposite internal tube surface. The liquid volume flux profile for this spray configuration is exhibited in Figure 17(c), which ranged from 0.06 to $0.82 \mathrm{~cm}^{3} / \mathrm{s} / \mathrm{cm}^{2}$, with a radial sample average of $0.045 \mathrm{~cm}^{3} / \mathrm{s} / \mathrm{cm}^{2}$. Following this series of dynamic spray and droplet measurements including exit and spill orifice flow rates, $\mathrm{Q}(1 / \mathrm{min})$, spray cone angle $(\theta)$ of droplet diameter, D32 $(\mu \mathrm{m})$, velocity, $\mathrm{D}_{\mathrm{v}}(\mathrm{m} / \mathrm{s})$ and liquid volume flux, $\mathrm{Q}_{\mathrm{f}}\left(\mathrm{cm}^{3} / \mathrm{s} / \mathrm{cm}^{2}\right)$, Table 3 was produced in summary. 
Table 3: Summary of dynamic spray and droplet measurements using a water pressure of $13 \mathrm{MPa}$

\begin{tabular}{|c|c|c|c|c|c|c|c|}
\hline \multirow[t]{2}{*}{ Atomiser Type } & \multicolumn{5}{|c|}{ Ambient condition } & \multicolumn{2}{|c|}{$\begin{array}{c}\text { within } \\
\text { simulated } \\
\text { PMMA tube }\end{array}$} \\
\hline & $\begin{array}{c}\text { Type } \\
\text { A }\end{array}$ & $\begin{array}{c}\text { Type } \\
\text { B }\end{array}$ & $\begin{array}{c}\text { Type } \\
\text { C }\end{array}$ & $\begin{array}{c}\text { Type } \\
\text { D }\end{array}$ & $\begin{array}{c}\text { Type B } \\
\text { Overlap }\end{array}$ & $\begin{array}{c}\text { Type } \\
\text { B }\end{array}$ & $\begin{array}{c}\text { Type } \\
\text { C }\end{array}$ \\
\hline $\begin{array}{c}\text { Cone angle } \\
\theta \text { (degree) }\end{array}$ & 34.7 & 42.7 & 49.2 & 54.2 & N/A & 42.7 & 49.2 \\
\hline $\begin{array}{l}\text { Penetration } \\
\text { d }(\mathbf{m m})\end{array}$ & 304 & 243 & 207 & 186 & 300 & 190 & 190 \\
\hline $\begin{array}{c}\text { Exit orifice flow rate } \\
Q_{e}(1 / \mathrm{min})\end{array}$ & 0.295 & 0.850 & 1.360 & 1.940 & 1.700 & 0.850 & 1.360 \\
\hline $\begin{array}{c}\text { Spill return orifice flow } \\
\text { rate } \\
Q_{s}(1 / \mathrm{min})\end{array}$ & 1.120 & 0.850 & 0.490 & 0.250 & 1.700 & 0.850 & 0.490 \\
\hline $\begin{array}{c}\text { Average droplet size } \\
\operatorname{D32}(\mu \mathrm{m})\end{array}$ & 17 & 26 & 29 & N/A & 54 & 34 & 39 \\
\hline $\begin{array}{l}\text { Average droplet velocity } \\
\text { Vd (m/s) }\end{array}$ & 13.50 & 21.41 & 13.50 & N/A & 6.50 & $\leq 0$ & 3.23 \\
\hline $\begin{array}{c}\text { Average liquid volume flux } \\
\text { Qf }\left(\mathrm{cm}^{3} / \mathrm{s} / \mathrm{cm}^{2}\right)\end{array}$ & 0.011 & 0.024 & 0.039 & N/A & 0.038 & 0.044 & 0.047 \\
\hline
\end{tabular}

\section{Conclusions}

- The numerous and exclusive experimental trials conducted in which the principle objectives of these "cold trials" were to characterize a series of Spill Return Atomizer (SRA) configurations and to assess their potential suitability for selection for the "hot trial" series of this study which will be presented in future publication.

- Table 2 is presented here again for convenience, provides a reminder of the critical orifice dimensions for SRA configuration types A, B, C and D.

- As a consequence of the flow rate trials the SRA Type D configuration was eliminated from the selection process due to flow irregularities. 
- Following this series of dynamic spray and droplet measurements including exit and spill orifice flow rates, Q (1/min), spray cone angle $(\theta)$ of droplet diameter, D32 $(\mu \mathrm{m})$, velocity, $\mathrm{D}_{\mathrm{v}}(\mathrm{m} / \mathrm{s})$ and liquid volume flux, Qf $\left(\mathrm{cm}^{3} / \mathrm{s} / \mathrm{cm}^{2}\right)$, were produced.

- The main objective of these "cold trials" was to characterize a number of SRA configurations and conformations as part of a selection and elimination process prior to the subsequent "hot trials" phase of this study. Six of the seven SRA's included in these "cold trials" were deemed suitable for use in the succeeding "hot trials".

\section{References}

CATLIN, C. 1991. Scale effects on the external combustion caused by venting of a confined explosion. Combustion and Flame, 83, 399-411. doi: https://doi.org/10.1016/00102180(91)90086-Q.

CORNIN, P. and WICKENS, M. J. 1986. A large scale experimental study of the conditions required to sustain high speed flame propagation in a flammable vapour cloud.

FLEMING, J. W. and SHEINSON, R. S. 2007. Chapter 4: Aerosol Properties. [Online]. Available: https://www.nist.gov/system/files/documents/el/fire_research/chapter-4.pdf

HARRIS, R. and WICKENS, M. 1989. Understanding vapour cloud explosions-an experimental study. Publ./Institution of gas eng.

HEALTH AND SAFETY EXECUTIVE (HSE) 2015. The Control of Major Accident Hazards Regulations 2015 (3rd edition). Available: https://www.hse.gov.uk/pubns/priced/1111.pdf

JOHNSON, D., SUTTON, P. and WICKENS, M. 1991. Scaled experiments to study vapour cloud explosions. Process Safety and Environmental Protection, 69, 76-84.

KAESEMANN, R. and FAHLENKAMP, H. 2002. The Meaning of Droplet-Droplet Interaction for the Wet Flue-Gas Cleaning Process. Chemical engineering \& technology, 25, 739-742. doi: https://doi.org/10.1002/15214125(20020709)25:7\%3C739::AID-CEAT739\%3E3.0.CO;2-7.

KASMANI, R., WILLACY, S., PHYLAKTOU, H. and ANDREWS, G. Selfaccelerating gas flames in large vented explosions that are not accounted for in current vent design. 
Proceedings of the 2nd International Conference on Safety and Environment in Process Industry, 2006.

LANE, W. 1951. Shatter of drops in streams of air. Industrial \& Engineering Chemistry, 43, 1312-1317. doi: https://doi.org/10.1021/ie50498a022.

NASR, G. and CONNOR, N. 2014. Natural Gas Engineering and Safety Challenges. Springer International Publishing, 402. doi: https://doi.org/10.1007/978-3-319$\underline{08948-5 .}$.

NASR, G., YULE, A., STEWART, J., WHITEHEAD, A. and HUGHES, T. 2011. A new fine spray, low flowrate, spill-return swirl atomizer. Proceedings of the Institution of Mechanical Engineers, Part C: Journal of Mechanical Engineering Science, 225, 897-908. doi: https://doi.org/10.1243\%2F09544062JMES2675.

SAPKO, M. J., FURNO, A. L. and KUCHTA, J. 1977. Quenching methane-air ignitions with water sprays, Dept. of the Interior, Bureau of Mines.

STEWART, J. 2011. Design and development of a novel spill return atomiser (SRA) disinfection system for healthcare environments. $\mathrm{PhD}$, University of Salford.

VAN WINGERDEN, K. and WILKINS, B. 1995. The influence of water sprays on gas explosions. Part 1: water-spray-generated turbulence. Journal of loss prevention in the process industries, 8, 53-59. doi: https://doi.org/10.1016/0950-4230(95)00002-I.

VAN WINGERDEN, K., WILKINS, B., BAKKEN, J. and PEDERSEN, G. 1995. The influence of water sprays on gas explosions. Part 2: mitigation. Journal of Loss Prevention in the Process Industries, 8, 61-70. doi: https://doi.org/10.1016/09504230(95)00007-N.

ZALOSH, R. and BAJPAI, S. 1982. Water fog inerting of hydrogen-air mixtures. International Nuclear Information System (INIS), 16. 